\title{
Does acoustic environment modify boldness and related life-history traits in field cricket nymphs?
}

\author{
Krisztina Petróczki ${ }^{1}$ - Anssi Vainikka ${ }^{2} \cdot$ Raine Kortet $^{2}$ \\ Received: 8 January 2018 / Revised: 11 February 2019 / Accepted: 1 March 2019 / Published online: 15 March 2019 \\ (C) The Author(s) 2019
}

\begin{abstract}
Between-individual differences in personality and life-history traits can arise from both genetic and environmental factors, with the latter possibly reflecting contrasting individual experiences during ontogeny. It is yet unclear how the acoustic environment may affect the development of boldness and related life-history traits such as growth rate, maturation age and longevity in species that normally rely on acoustic cues to adjust their behaviours. We studied if long-term exposure of field cricket Gryllus integer nymphs to traffic noise or acoustic conspecific signalling would affect the level or repeatability of boldness or life history traits. An integrative boldness score was statistically significantly repeatable in control and cricket sound groups, but not in the traffic noise group. However, our data did not show any effect of acoustic treatment on individual boldness. Acoustic treatments had no effects on life-history traits, either. Future studies are needed to confirm whether the acoustic environment could affect the development of personality and behavioural consistency.
\end{abstract}

Keywords Noise pollution $\cdot$ Traffic noise $\cdot$ Acoustic environment $\cdot$ Animal personality $\cdot$ Boldness $\cdot$ Gryllus integer

\section{Introduction}

Animals inhabit an acoustic environment that encompasses various types of information originating from biotic (conspecifics, individuals from other taxa, predators, etc.) or abiotic (rain, waterfall, wind-induced vegetation movement, noises produced by human technologies, etc.) sources. A wide range of animal taxa use the acoustic channel of their surrounding environment to scan their habitat for cues about the presence of predators and prey, and signals that convey information about or toward conspecifics, including rivals and potential mates (Smith and Harper 2003; Bradbury and Vehrencamp 2013). However, the acoustic environment can also affect animal behaviours negatively, for example, through interference with acoustic communication system (Forman and Alexander

Krisztina Petróczki

kriszti3na@gmail.com

1 Department of Evolutionary Zoology and Human Biology MTA-DE 'Lendület' Behavioural Ecology Research Group, University of Debrecen, Debrecen, Hungary

2 Department of Environmental and Biological Sciences, University of Eastern Finland, Joensuu, Finland
1998). Moreover, the acoustic environment is known to affect life-history traits (DiRienzo et al. 2012) and to potentially favour and modify certain personality traits (Lowry et al. 2013). Noise pollution, such as traffic noise, can mask important natural acoustic information, which could imply that living in a high noise level urban habitat represents a challenge for many animal taxa (Barber et al. 2010; Laiolo 2010; Brumm 2013; Farina 2014; Holt and Johnston 2015).

Few studies so far have assessed how behavioural traits and any associated life-history traits respond to anthropogenic acoustic pollution or how variability in personality traits affects responses to this type of noise (Naguib et al. 2013). There is direct and indirect evidence that many animals, like sanderlings (Burger and Gochfeld 1991), red foxes (Baker et al. 2007), coyotes, bobcats (Tigas et al. 2002) and black bears (Beckmann and Berger 2003) alter their behavioural activity patterns due to anthropogenic acoustic disturbances. Animals also show adaptations to louder environmental conditions in urban settings. These adaptations can include physiological (e.g. neuroendocrinological, immunological, cardiovascular, metabolic, reproductive) and behavioural changes like modified activity patterns or avoidance of certain areas (Popper 2003; Tyack 2008; Barber et al. 2010; Kight and Swaddle 2011). Noisy conditions can also trigger alterations in acoustic communication, as demonstrated in fishes (Radford et al. 
2014) and birds (Brumm and Slabbekoorn 2005). The studies cited above illustrate many immediate changes in animal behaviour and physiology as response to acoustic stimuli in general. However, responses to the acoustic environment may also affect developmental trajectories, with long-lasting effects to both personality and life-history traits.

Recent research in animal behaviour has, in fact, been focusing on behavioural syndromes and consistent individually repeatable behaviours, i.e. animal personality traits (Dingemanse and Réale 2005; Sih and Bell 2008; Dingemanse et al. 2010; Wilson et al. 2010; Niemelä et al. 2013a; Niemelä et al. 2013b). Among individuals, differences in personality traits like boldness can arise from both genetic and environmental factors (Dingemanse and Réale 2005; Dingemanse et al. 2010; Kortet et al. 2014; Kortet et al. 2015), and the recent data indicate that experiences during ontogeny affect the development of animal personality (Dingemanse et al. 2009; Stamps and Groothuis 2010; DiRienzo et al. 2012; Niemelä et al. 2012b; Niemelä et al. 2012c; DiRienzo et al. 2015). In general, the evolution of consistent animal personalities and reacting reliably to environmental information are likely linked in many ways (Niemelä et al. 2013b). In a predator-prey context, animal personalities have evolutionary importance by altering growth-mortality trade-offs along risk gradients (e.g. Stamps 2007; Kortet et al. 2010). Different levels of noise pollution could intensify or milden the perceived risk gradient to which animals must adapt or acclimatise. Perceiving acoustic cues from predators is crucial, and noise pollution has a strong potential to lead to lower perceived predation risk. In populations exposed to elevated predation risk, natural selection likely acts to favour stronger anti-predator behaviour (Chivers et al. 2001; Kortet et al. 2007). In some species, sexual selection is partially dependent on acoustic signals and personality seems to be coupled with courtship display and mate choice strategies (Kortet et al. 2012).

Being bold or shy has different costs and benefits in varying habitats. Especially in species that use acoustic sexual signalling, bold individuals have the benefit of better reproduction success, as their chances of finding a mating partner may be better compared to shy individuals because the bold ones may be spending more time out of their hiding places, but simultaneously be exposed more often to predators (Kortet et al. 2007; Kortet et al. 2012). In general, shy individuals tend to take less risks and avoid more effectively predation by hiding longer than bold ones, and therefore, they may have less chances for activities that directly improve growth or reproductive success (Sih et al. 2004; Hedrick and Kortet 2012a).

Moreover, boldness often forms behavioural syndromes with other behaviours, for instance, aggressiveness (Sih et al. 2004). This aggression-boldness syndrome means that a bolder individual behaves more aggressively (Kortet and Hedrick 2007). Being bold could be advantageous for males in lowdensity conditions, as they could effectively fight for access to females in this kind of surroundings (Simmons 1986; Loher and Dambach 1989; Ogawa and Sakai 2009). However, the decrease of boldness could reduce the cost of male-male competition in high-density populations (DiRienzo et al. 2012). Additionally, personality traits also often correlate with lifehistory variables (e.g. maturation age, longevity and adult size) along pace-of-life continua (Wolf et al. 2007; Réale et al. 2010; Krams et al. 2017). For instance, individuals with early maturation have better fitness when they are bold rather than shy since boldness may increase their chances of a successful early reproduction. Early reproduction is important since these individuals are in a fast pace-of-life, meaning that they die younger than individuals with late maturation (Niemelä et al. 2012b). Therefore, when traffic noise overlaps natural acoustic information, such as information about population density and hence competitive levels, it seems plausible that noise pollution could affect developmental trajectories. In other words, by inducing a wrong perception of conspecific density, traffic noise could induce the formation of non-adaptive animal personalities and their related life history traits. Such types of long-lasting responses to traffic noise are not yet well studied.

Members of the Gryllidae taxon are excellent model animals for studying the effects of acoustic environment and anthropogenic sound pollution on behavioural development since (1) juveniles do not sing but they often live in polluted anthropogenic habitats, from which they can hardly escape as they do not fly (Cranshaw and Shetlar 2018), (2) males use conspicuous courtship song for attracting conspecific females (e.g. Hedrick and Kortet 2012b; Bertram et al. 2013), and (3) boldness can be measured easily in exploratory context through measuring the time to emerge from a shelter (Hedrick and Kortet 2012a). Moreover, (4) a recent study by DiRienzo et al. (2012) demonstrated that acoustic environment can affect both growth rate and behavioural traits such as aggressiveness and dominance in the field cricket Gryllus integer. DiRienzo et al. (2012) found that cricket juveniles with large body mass reared in conspecific acoustic signals (high-density environment) became larger adults than smaller juveniles or juveniles of any initial size that were reared in silence (low-density environment). In addition, cricket nymphs reared in calling chirp exposure environment were less aggressive toward conspecifics and were less likely to become dominant as adults than those reared in silence. Furthermore, (5) Niemelä et al. (2012b) found that personality traits in $G$. integer form integrative pace-of-life syndromes with life-history traits, with bolder individuals growing faster and dying younger than shyer ones.

As field crickets often grow and live in noise polluted areas, they have to manage their signalling under high- and low-frequency traffic noise, which is mainly below $2000 \mathrm{~Hz}$ (Patricelli and Blickley 2006; Warren et al. 2006). Crickets are potentially well-adapted to sense this frequency band because they are able to perceive at least low-frequency sounds through their subgenual organ, a group of sensilla in the 
proximal tibiae of the forelegs and their tracheal organ in the mesothoracic legs that also increases sensitivity of auditory receptors (Huber et al. 1989). Kämper (1984) suggested that ascending abdominal interneuron from cerci responds to $30 \mathrm{~Hz}$ sound frequency in crickets.

In this study, we investigated whether traffic noise pollution has an effect on the development of a personality trait and on three life-history traits of $G$. integer nymphs. We asked, whether nymphs exposed to traffic noise, compared to nymphs exposed to conspecific sound or silence, will turn into shyer or bolder adults when emerging from a shelter in an exploratory task. We also asked whether the traffic noise treatment will differentially affect growth, maturation age and longevity. Due to the aggression-boldness syndrome (Kortet and Hedrick 2007; DiRienzo et al. 2012), and because increased traffic noise pollution may decrease crickets' acoustic perception of conspecific density, we predicted that crickets would become bolder in traffic noise exposure, i.e. spend less time as motionless and take less time to emerge from shelter - than the ones exposed to conspecific sound. However, as traffic noise is an unknown source of sound (from the crickets' points of view), with potential non-neutral effects (compared to silence), it could trigger random developmental trajectories (among individuals) and/or inconsistent personalities (within individuals). We, therefore, predicted that crickets in the traffic noise group would on average become less bold than the ones exposed to silence and show reduced behavioural repeatability than crickets in the other two groups. If the exposures to the sound treatments affect crickets' boldness, we predicted that also life-history traits could be impacted, due to pace-of-life syndromes (Niemelä et al. 2012b). Therefore, if crickets exposed to traffic noise become bolder than individuals exposed to conspecific sounds, they should also become smaller (DiRienzo et al. 2012), mature earlier and die younger (Niemelä et al. 2012b), while crickets exposed to conspecific calling would become larger, mature later and die older.

\section{Materials and methods}

\section{Study animals}

We used laboratory-reared field crickets (G. integer) from bulk stock originating from a wild population (Davis, CA). The crickets were originally collected from the wild in 2008, and the stock was supplemented in 2010 with offspring of additional wild-caught animals. The cricket stock has since been maintained at the University of Eastern Finland (Joensuu, Finland) in large plastic containers under $26{ }^{\circ} \mathrm{C}, 12: 12 \mathrm{~h}$ light/dark photoperiod for multiple generations. Individuals in this experiment were separated from this laboratory stock as nymphs at the age of 3 weeks (when they are typically around their third instar stage), housed individually in plastic containers (length $128 \mathrm{~mm} \times$ width $98 \mathrm{~mm} \times$ height $73 \mathrm{~mm}$ ) and provided with food (reindeer feed pellets, fish feed pellets) and water ad libitum. Each container was covered with a plastic lid with a hole in the middle covered with a metal net for ventilation and supplied with cardboard as a shelter. For the life-history information, the dates of final moult (maturation) and natural death were recorded for each individual. On average, the crickets matured at the age of $124.03 \pm$ S.D. 30.7 days. Sexes were not distinguished in this study.

\section{Boldness assays}

In the boldness assays, we used established methods (modified from e.g. Hedrick 2000; Kortet et al. 2007; Niemelä et al. 2012a, 2012b). The first trial series for each individual nymph was performed after 3 weeks of individual rearing in the plastic containers, and the second trial series followed immediately. The tests were conducted in a sound-proof room at $25^{\circ} \mathrm{C}$. To reduce visual disturbance by the observer, dim red light was used because crickets perceive long wavelengths (red) as dark (Briscoe and Chittka 2001). Tests were performed in opened pellucid plastic arenas (length $118 \mathrm{~mm} \times$ width $118 \mathrm{~mm} \times$ height $112 \mathrm{~mm}$ ) placed into Styrofoam boxes (length $282 \mathrm{~mm} \times$ width $270 \mathrm{~mm} \times$ height $207 \mathrm{~mm}$, wall thickness $15 \mathrm{~mm}$ ) covered with Plexiglas to minimise possible visual and acoustic disturbances. The focal cricket was placed into a clean plastic pellucid experimental tube (inner diameter $25.5 \mathrm{~mm}$, length $51 \mathrm{~mm}$ ) that was closed on both ends with a plastic lid. A trial was started by placing the tube lengthwise in the middle of the arena for a $2 \mathrm{~min}$ acclimatisation period. Observations started after the careful removal of the plastic lid from both ends of the tube and placing of a Plexiglas on the top of the experimental arena to prevent crickets from escaping. Two trials in separate Styrofoam boxes were conducted simultaneously. Three behaviours were recorded: (1) time to become active, a behavioural antipredator response indicating duration of handling-induced freezing; (2) time until the head emerged from shelter; and (3) time to full emergence from shelter. The last two variables measure boldness in an exploratory context (Niemelä et al. 2012b), as prior to emerging, the crickets had time to scan their novel environment. Crickets had $15 \mathrm{~min}$ to complete the whole trial, and when they did not emerge from the tube within $15 \mathrm{~min}$, they were assigned the maximal time for each behaviour. Behavioural data was recorded using AV Bio-Statistics 4.9 (http://www. kotikone.fi/ansvain/). Each cricket $(N=110)$ was assayed three times with 2-day intervals between the trials.

\section{Acoustic treatments}

After the first trial series, the crickets $(N=108)$ were randomly divided into three treatment groups: One group was exposed to a choir of calling crickets (five different groups of calling 
crickets recorded in the laboratory with a ZoomH4n sound recorder); the second group was exposed to traffic noise (roadside noise recorded with a ZoomH4n sound recorder); and the third group served as unexposed controls. Cricket choir calling was used because crickets are potentially exposed to various intensities of conspecific song in the wild. The dominant frequency of the calling recordings was around $4500 \mathrm{~Hz}$ (analysed using Audacity program version 2.1.0) that can be considered high-frequency sound. The dominant frequencies of the traffic noise recordings were around $100 \mathrm{~Hz}$ and $1200 \mathrm{~Hz}$, considered low- and intermediate-frequency sounds, respectively. The crickets of each treatment were placed into three large lockable Styrofoam insulator boxes (inner length $352 \mathrm{~mm} \times$ inner width $274 \mathrm{~mm} \times$ inner height $\mathrm{mx} 360 \mathrm{~mm}$, thickness $22 \mathrm{~mm}$ ) to reduce other noise disturbance. One insulator box contained 12 crickets, individually housed in plastic boxes. Bulk loudspeakers ( $8 \Omega$, frequency range 70 $17,000 \mathrm{~Hz}$, SP-Elektroniikka, Oulu, Finland) were fixed onto the inner side of the cover of the Styrofoam boxes, allowing the noise stimulus to be broadcast toward the crickets. The two noise types were played back from a computer through a bulk computer loudspeaker amplifier (decibel levels of the playbacks naturally varying from 45 to $70 \mathrm{~dB}$ ) for 25 days. After both the first and the second trial series, the length of the nymphs (from the top of head to the end of abdomen) was measured with a digital calliper and body mass with an analytical scale. The crickets were immobilised with $\mathrm{CO}_{2}$ prior to these measurements.

\section{Statistical analyses}

The distribution of each variable was assessed graphically from histograms. Behavioural response variables were positively skewed and therefore $\operatorname{Ln}(x+1)$-transformed. As the behavioural variables all correlated negatively with the time of day at recording (Pearson's correlation, $R=-$ $0.191--0.174, N=630, P<0.001$ ), we fitted a linear regression to explain the variation with the time of the day (as a minute from midnight) using the three behavioural measurements from the first trial series that were not confounded with the acoustic treatments. The respective linear regression equations were then used to calculate the time-independent (residual) behavioural measures for both the first and second trial series. Principal component analysis (PCA) was then used to combine the information in the three formed residual measurement-timeindependent behavioural variables as this approach integrates the information in multiple individual behaviours that may also be correlated due to the experimental procedure (e.g. Niemelä et al. 2013a; Kekäläinen et al. 2014; Kortet et al. 2014). Here, the PCA was used to calculate a boldness score, which was the response variable in a linear mixed effects model (LME) with the fixed effects of treatments (main effects of treatment, before vs. after the treatment, and their interaction) and potential linear covariates (individual length before the behavioural assays and maturation age), and trial number (1-6) as a repeated variable with first-order autoregressive (AR1) covariance structure. Individual intercept and housing box ID (block in which the individual boxes were maintained, three temporally simultaneous replicates per treatment) were included as random factors with identity type covariance structure to account for the among-individual dependence within boxes. We also fitted a random regression model with individual slopes and respective main effects, but the random regression model showed a poor fit to the data and convergence problems due to fact that individual changes over the course of study were not linear (AIC of the random regression model was 2382.62, compared to the AIC of the used model at 1765.88). Model residuals were examined for normality using histograms.

Secondly, standard ANOVAs were used to examine the effect of treatments on the life-history traits. PCA, ANOVAs and LMEs were fitted in IBM SPSS Statistics 23.0.0.2 (IBM Corp.). Finally, repeatability of the principal component score in different treatment groups was calculated using the package ICC (by M. Wolak) in R 3.2.0 (R Core Team, R Foundation for Statistical Computing, Vienna, Austria) following Lessells and Boag (1987). This analysis takes into account both within-individual and between-individual repeatability over the duration of the study.

\section{Results}

\section{Intercorrelations among variables and the repeatability of behaviour}

All three measured behavioural response variables were combined into one principal component that explained most of the variance in behaviour and reflected boldness (Table 1). The component values were statistically significantly repeatable in control and cricket sound groups but not in the traffic noise group (Fig. 1).

Table 1 Results of principal component analysis (PCA) on the three recorded behaviours. $N=103$ individuals. The PCA explained $85.15 \%$ of the total variance. The loadings reflect the contribution of each original variable to the formed component

\begin{tabular}{ll}
\hline Variable & Loading \\
\hline Latency to become active & 0.879 \\
Latency to emerge from shelter with head & 0.963 \\
Latency to emerge from shelter with whole body & 0.924 \\
\hline
\end{tabular}




\section{Effect of treatments on boldness}

None of the initially included covariates were statistically significant, and thus the model was simplified to include only the categorical factors (Table 2, Fig. 2). The interaction term indicating a treatment effect was not statistically significant (Table 2). The null model including only the random factors and intercept had lower AIC value than the reported model (Table 2), further supporting lack of any treatment effects (1758.93 vs. 1765.88$)$.

\section{Effect of treatments on life history}

The sound treatments did not affect maturation age $\left(F_{2,101}=\right.$ $0.179, P=0.837)$, longevity $\left(F_{2}, 100=0.126, P=0.881\right)$ or length at death $\left(F_{2,100}=1.497, P=0.229\right)$.

\section{Discussion}

The present results are equivocal, but we found indications that animal personality development may be impacted by the acoustic environment, and by traffic noise in particular. First, and as predicted, the boldness score was statistically significantly repeatable in control and cricket sound groups, but not in the traffic noise group. This finding is in line with the idea that behavioural repeatability estimates can be very sensitive to ecological and environmental factors that individuals

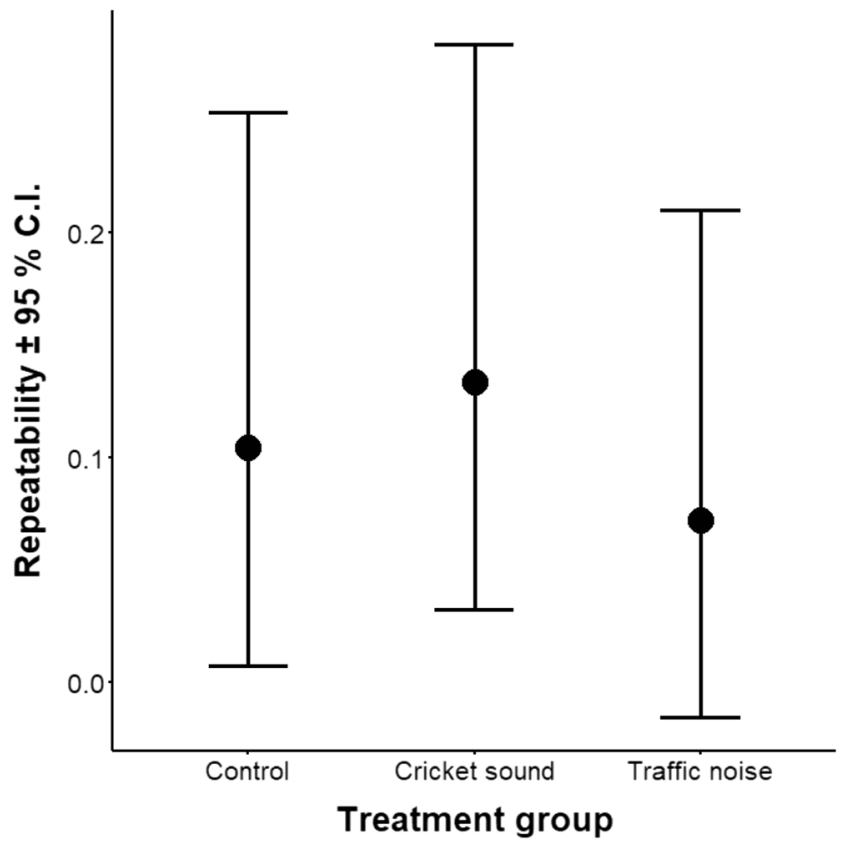

Fig. 1 Repeatability of the boldness-related personality variation in different treatment groups with $95 \%$ confidence intervals (C.I.). If C.I. is non-different from zero, the repeatability hypothesis is rejected. The component values were statistically significantly repeatable in control and cricket sound groups but not in the traffic noise group
Table 2 Linear mixed effect model with the treatment effects (AIC $=$ 1765.88, null model AIC $=1758.93)$. $d f$ refers to degrees of freedom. Treatment $=$ traffic noise, cricket song treatment and silent control; BeforeAfter $=$ trial series before and after noise treatment. $N=103$ individuals

\begin{tabular}{lllll}
\hline Explanatory variable & $F$ & Numerator $d f$ & Denominator $d f$ & $P$ \\
\hline Intercept & 0.034 & 1 & 100.84 & 0.854 \\
BeforeAfter & 0.226 & 1 & 228.57 & 0.635 \\
Treatment & 0.600 & 2 & 100.84 & 0.551 \\
Treatment $\times$ BeforeAfter & 1.614 & 2 & 228.574 & 0.201 \\
\hline
\end{tabular}

encounter throughout their lives (Dirienzo et al. 2016) and supportive of our hypothesis that traffic noise is not neutral to crickets (compared to silence) and can consistently disrupt developmental trajectories of personality. What the consequences are to individual fitness when crickets are not consistently bold or shy during their adult life deserve further investigation.

Second, our results suggest that conspecific acoustic signals might not have an important role in the development of consistent behaviours (but see DiRienzo et al. 2012), as we found no effect of treatment (before vs. after exposure to sound) with conspecific sounds in developmental trajectories of boldness. These results did not support our prediction that crickets would decrease boldness, whereas they have been observed to decrease their aggressiveness in response to conspecific sounds (DiRienzo et al. 2012), which may indicate that an aggression-boldness syndrome does not occur in $G$. integer or, more likely, that it did not occur under the

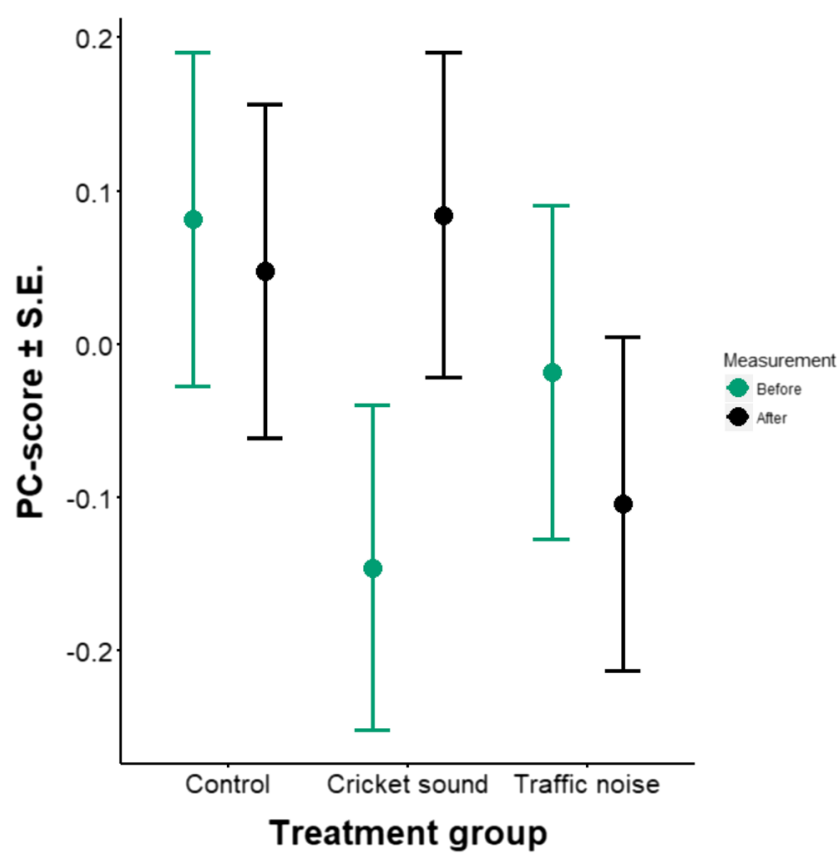

Fig. 2 Estimated marginal mean personality principal component scores (PC-score) \pm standard error (S.E.) according to the model with the treatment effects. None of the effects were statistically significant 
conditions of our experiments. In fact, our methods differed from those of DiRienzo et al. (2012) as we used a mix of five choruses for the conspecific sound treatment, but DiRienzo et al. (2012) used a mix of five songs. This means that in our experiment, conspecific density was much higher than in DiRienzo et al. (2012), suggesting that in such circumstances, no significant decrease in boldness is especially advantageous. Perhaps under very high density, where many males will probably not be able to mate, being bold will remain an advantage. In fact, we found a (non-significant) increase, instead of a decrease, in the boldness score after the treatment with conspecific sound. This hypothesis thus seems to deserve further investigation.

Third, our results also contradict our original prediction that traffic noise would impact boldness compared to silence and conspecific sound treatments. Because all three treatment groups did not differ between each other, the only possible conclusion is that under the conditions of our experiments, traffic noise had no impact on developmental trajectories of cricket personalities. Fourth, the sound treatments did not affect the life-history traits studied here. This suggests that lifehistory traits have no correlation with boldness, apparently rejecting the pace-of-life continuum hypothesis. However, since we did not find significant differences in boldness among treatments, no effects on life-history traits could have been expected either. In that sense, our results were consistent. This also means that the pace-of-life continuum hypothesis under traffic noise effect remains to be tested.

Furthermore, since we did not include in our experiments a treatment with acoustic cues from predators, we cannot compare whether crickets exposed to traffic noise would have become bolder than crickets from the predator treatment. In a natural setting, traffic noise may hide predator cues; thus, becoming bolder under those conditions would not be adaptive. As this may significantly affect cricket survival, this topic requires further investigation. A sex effect may also be possible, as different sexes may have different selection pressures in the wild. Unfortunately, in the present study, the sexes were not distinguished, which is why our results should be interpreted with caution, as possible male and female opposing developmental trajectories could have masked any treatment effect. It would be difficult to estimate how our experimental sound treatments correspond with those sounds that crickets experience in the field, as the situation in the wild depends naturally on the distance the crickets are located from the sound source.

Being bold could be advantageous for males in "nocalling", less competitive, conditions as they could effectively fight for the relatively few females (Simmons 1986; Loher and Dambach 1989; Ogawa and Sakai 2009). Decrease of boldness of field crickets in "calling" conditions could reduce costs of male-male competition in high-density populations (DiRienzo et al. 2012) and costs of increased predation risk such as risk of injury (Marler et al. 1995; Michener and McLean 1996). Boldness often forms behavioural syndromes with other behaviours, for instance, aggressiveness (Sih et al. 2004). This aggression-boldness syndrome in $G$. integer suggests that a less bold male behaves less aggressively which could lead to survival benefits when predation risk is high (Kortet and Hedrick 2007).

There was no change in boldness in the control group where crickets were tested without noise stimuli. The same crickets tested over time were younger in the first trial series than in the second trial series, and the differences between boldness scores on these conditions could reflect natural changes during ontogeny. Hedrick and Kortet (2012a) and Niemelä et al. (2012b) have demonstrated that older, mature crickets behave more shyly than young nymphs, presumably because adults have to compensate for their conspicuous mating behaviour incurring increased predation risk (Hedrick 2000). As reproductive adults, mature crickets have to be more alert than juveniles (Wolf et al. 2007). Moreover, younger crickets should apply different strategies to avoid predators (Sih et al. 2003; McPeek 2004). The different results compared to Hedrick and Kortet (2012a) might partially be explained by small differences in the methodology, as in the present work, we used experimental vials that were open on both sides after the connected plastic lids were removed, while in the work by Hedrick and Kortet (2012a), only one side of the vial was open.

Life-history variables (e.g. maturation time and adult size) often correlate with personality traits along pace-of-life (POL) continua (Wolf et al. 2007; Réale et al. 2010; Krams et al. 2017). For example, individuals with early maturation should have better fitness when being bold rather than shy, because bold individuals might not reach the required age for late maturation as often as shy ones (Niemelä et al. 2012b). However, our study did not show any noise treatment effect on life-history.

As our study crickets were about 4 weeks old when the acoustic treatment started, it could be possible that their hearing ability for airborne cues was not fully developed at that time (Staudacher 2009). Moreover, one might argue that crickets may not hear acoustic cues of low or intermediate frequency. However, airborne sound can also vibrate the substrate, so juvenile crickets may not need fully developed tympanal membranes to detect acoustic environmental cues. On the other hand, even partially functioning tympanal membranes can potentially mediate effects in juvenile crickets. These mechanisms could explain our results and also the results by DiRienzo et al. (2012), as possible substrate-mediated vibrations depend greatly on the substrate materials on which an individual is located. Transduction effects may be great on leaf litter but are unlikely to be a major factor on solid ground. Here, the crickets were kept in plastic containers equipped with cardboard. Both the plastic container and the cardboard 
may resonate with the sound, which could have mediated the indirect detection of acoustic cues in the present study.

In conclusion, our results suggest that the acoustic environment and traffic noise, in particular, may not have a strong effect on the development of boldness and related life history traits of field cricket nymphs. However, due possibly to methodological differences with other studies, as well as sex differences and predator effects that we did not analyse here, future work should keep analysing traffic noise influences on the development of aggression-boldness and pace-of-life syndromes in $G$. integer.

Acknowledgements We thank Leena Pääkkönen and Julia Keronen for their help in the laboratory. We thank Sirpa Kaunisto, Adrian Ng, Chris Elvidge, and three anonymous reviewers for their valuable feedback on the manuscript.

Funding information Open access funding provided by University of Debrecen (DE). The study was supported by the Hungarian Scientific Research Fund (OTKA, \#K81929; K.P.), by Campus Hungary Program, which is supported by the European Union and co-financed by the European Social Fund (K.P.), and by the Finnish Cultural Foundation (R.K.).

\section{Compliance with ethical standards}

Conflict of interest The authors declare that they have no conflict of interests.

Human and animal rights and informed consent We conducted this study in accordance with the Finnish legislation. All applicable institutional and/or national guidelines for the care and use of animals were followed.

Open Access This article is distributed under the terms of the Creative Commons Attribution 4.0 International License (http:// creativecommons.org/licenses/by/4.0/), which permits unrestricted use, distribution, and reproduction in any medium, provided you give appropriate credit to the original author(s) and the source, provide a link to the Creative Commons license, and indicate if changes were made.

\section{References}

Baker PJ, Dowding CV, Molony SE, White PCL, Harris S (2007) Activity patterns of urban red foxes (Vulpes vulpes) reduce the risk of traffic-induced mortality. Behav Ecol 18:716-724

Barber JR, Crooks KR, Fristrup KM (2010) The costs of chronic noise exposure for terrestrial organisms. Trends Ecol Evol 25:180-189

Beckmann JP, Berger J (2003) Rapid ecological and behavioural changes in carnivores: the responses of black bears (Ursus americanus) to altered food. J Zool 261:207-212

Bertram SM, Thomson IR, Harrison SJ, Ferguson GL, Fitzsimmons LP (2013) Adaptive plasticity in wild field cricket's acoustic signalling. PLoS One 8(7):e69247. https://doi.org/10.1371/journal.pone. 0069247

Bradbury JW, Vehrencamp SL (2013) Principles of animal communication. Sinauer Associates, Sunderland
Briscoe AD, Chittka L (2001) The evolution of color vision in insects. Annu Rev Entomol 46(1):471-510

Brumm H (2013) Animal communication and noise. Springer, Dordrecht Brumm H, Slabbekoorn H (2005) Acoustic communication in noise. Adv Study Behav 35:151-209

Burger J, Gochfeld M (1991) Human activity influence and diurnal and nocturnal foraging of sanderlings (Calidris alba). Condor 93:259269

Chivers DP, Wildy EL, Kiesecker JM, Blaustein AR (2001) Avoidance response of juvenile pacific treefrogs to chemical cues of introduced predatory bullfrogs. J Chem Ecol 27(8):1667-1676

Cranshaw W, Shetlar D (2018) Garden insects of North America: the ultimate guide to backyard bugs. Princeton University Press, Princeton

Dingemanse NJ, Réale D (2005) Natural selection and animal personality. Behaviour 142:1159-1184

Dingemanse NJ, Van der Plas F, Wright J, Réale D, Schrama M, Roff DA, Van der Zee E, Barber I (2009) Individual experience and evolutionary history of predation affect expression of heritable variation in fish personality and morphology. Proc R Soc Lond B 276:12851293

Dingemanse NJ, Kazem AJN, Réale D, Wright J (2010) Behavioural reaction norms: animal personality meets individual plasticity. Trends Ecol Evol 25:81-89

DiRienzo N, Pruitt JN, Hedrick AV (2012) Juvenile exposure to acoustic sexual signals from conspecifics alters growth trajectory and an adult personality trait. Anim Behav 84(4):861-868

DiRienzo N, Niemelä PT, Skog A, Vainikka A, Kortet R (2015) Juvenile pathogen exposure affects the presence of personality in adult field crickets. Front Ecol Evol 3(36):1-10. https://doi.org/10.3389/fevo. 2015.00036

DiRienzo N, Niemelä PT, Hedrick AV, Kortet R (2016) Adult bacterial exposure increases behavioral variation and drives higher repeatability in field crickets. Behav Ecol Sociobiol 70:1941-1947

Farina A (2014) Soundscape ecology. Springer, Dordrecht

Forman RT, Alexander LE (1998) Roads and their major ecological effects. Ann Rev Ecol System 29(1):207-231

Hedrick AV (2000) Crickets with extravagant mating songs compensate for predation risk with extra caution. Proc R Soc Lond B 267(1444): 671-675

Hedrick AV, Kortet R (2012a) Sex differences in the repeatability of boldness over metamorphosis. Behav Ecol Sociobiol 66(3):407-412

Hedrick AV, Kortet R (2012b) Effects of body size on selectivity for mating cues in different sensory modalities. Biol J Linn Soc 105: $160-168$

Holt DE, Johnston CE (2015) Traffic noise masks acoustic signals of freshwater stream fish. Biol Conserv 187:27-33

Huber F, Moore TE, Loher W (1989) Cricket behaviour and neurobiology. In: Cornell University press. Ithaca, New York

Kämper G (1984) Abdominal ascending interneurons in crickets: responses to sound at the $30-\mathrm{Hz}$ calling-song frequency. J Comp Physiol A Neuroethol Sens Neural Behav Physiol 155(4):507-520

Kekäläinen J, Lai Y-T, Vainikka A, Sirkka I, Kortet R (2014) Do brain parasites alter host personality? - experimental study in minnows. Behav Ecol Sociobiol 68:197-204

Kight CR, Swaddle JP (2011) How and why environmental noise impacts animals: an integrative, mechanistic review. Ecol Lett 14:10521061

Kortet R, Hedrick AV (2007) A behavioural syndrome in the field cricket Gryllus integer: intrasexual aggression is correlated with activity in a novel environment. Biol J Linn Soc 91(3):475-482

Kortet R, Rantala MJ, Hedrick A (2007) Boldness in anti-predator behaviour and immune defence in field crickets. Evol Ecol Res 9(1): 185-197

Kortet R, Hedrick AV, Vainikka A (2010) Parasitism, predation and the evolution of animal personalities. Ecol Lett 13(12):1449-1458 
Kortet R, Niemelä PT, Vainikka A, Laakso J (2012) Females prefer bold males; an analysis of boldness, mate choice, and bacterial resistance in the field cricket Gryllus integer. Ecol Parasit Immun 1:1-6 ID 235580

Kortet R, Vainikka A, Janhunen M, Piironen J, Hyvärinen P (2014) Behavioral variation shows heritability in juvenile brown trout Salmo trutta. Behav Ecol Sociobiol 68(6):927-934

Kortet R, Sirkka I, Lai YT, Vainikka A, Kekäläinen J (2015) Personality differences in two minnow populations that differ in their parasitism and predation risk. Front Ecol Evol 3(9):1-8. https://doi.org/10. 3389/fevo.2015.00009

Krams IA, Niemelä PT, Trakimas G, Krams R, Burghardt GM, Krama T, Kuusik A, Mänd M, Rantala MJ, Mänd R, Kekäläinen J, Sirkka I, Luoto S, Kortet R (2017) Metabolic rate associates with, but does not generate covariation between, behaviours in western stuttertrilling crickets, Gryllus integer. Proc R Soc B 284(1851):20162481

Laiolo P (2010) The emerging significance of bioacoustics in animal species conservation. Biol Conserv 143:1635-1645

Lessells CM, Boag PT (1987) Unrepeatable repeatabilities: a common mistake. Auk 04:116-121

Loher W, Dambach M (1989) Reproductive behavior. In: Huber F, Moore TE, Loher W (eds) Cricket behavior and neurobiology. Comstock Publishing, New York, pp 43-82

Lowry H, Lill A, Wong B (2013) Behavioural responses of wildlife to urban environments. Biol Rev 88(3):537-549

Marler CA, Walsberg G, White ML, Moore M, Marler CA (1995) Increased energy expenditure due to increased territorial defense in male lizards after phenotypic manipulation. Behav Ecol Sociobiol 37(4):225-231

McPeek MA (2004) The growth/predation risk trade-off: so what is the mechanism? Am Nat 163(5):88-111

Michener GR, McLean IG (1996) Reproductive behaviour and operational sex ratio in Richardson's ground squirrels. Anim Behav 52(4): $743-758$

Naguib M, van Oers K, Braakhuis A, Griffioen M, de Goede P, Waas JR (2013) Noise annoys: effects of noise on breeding great tits depend on personality but not on noise characteristics. Anim Behav 85:949 956

Niemelä PT, DiRienzo N, Hedrick AV (2012a) Predator-induced changes in the boldness of naïve field crickets, Gryllus integer, depends on behavioural type. Anim Behav 84(1):129-135

Niemelä PT, Vainikka A, Hedrick AV, Kortet R (2012b) Integrating behaviour with life history: boldness of the field cricket, Gryllus integer, during ontogeny. Funct Ecol 26(2):450-456

Niemelä PT, Vainikka A, Lahdenperä S, Kortet R (2012c) Nymphal density, behavioral development, and life history in a field cricket. Behav Ecol Sociobiol 66:645-652

Niemelä PT, Dingemanse N, Alioravainen N, Vainikka A, Kortet R (2013a) Personality pace-of-life hypothesis: testing genetic associations among personality and life-history. Behav Ecol 24:935-941

Niemelä PT, Vainikka A, Forsman JT, Loukola OJ, Kortet R (2013b) How does variation in the environment and individual cognition explain the existence of consistent behavioural differences? Ecol Evol 3(2):457-464
Ogawa Y, Sakai M (2009) Calling and courtship behaviors initiated by male-male contact via agonistic encounters in the cricket Gryllus bimaculatus. Zool Sci 26:517-524

Patricelli GL, Blickley JL (2006) Avian communication in urban noise: causes and consequences of vocal adjustment. Auk 123:639-649

Popper AN (2003) Effects of anthropogenic sounds on fishes. Fisheries 28:24-31

Radford AN, Kerridge E, Simpson SD (2014) Acoustic communication in a noisy world: can fish compete with anthropogenic noise? Behav Ecol 25:1022-1030

Réale D, Garant D, Humphries MM, Bergeron P, Careau V, Montiglio PO (2010) Personality and the emergence of the pace-of-life syndrome concept at the population level. Phil Trans Royal Soc B 365(1560): 4051-4063

Sih A, Bell AM (2008) Insights for behavioral ecology from behavioral syndromes. - in: advances in the study of behavior (eds Brockmann, H.J., Roper, T.J., Naguib, M., Wynne-Edwards, K.E., Barnard, C. \& Mitani, J.C.). Academic Press, San Diego, 38. p. 227-281

Sih A, Kats LB, Maurer EF (2003) Behavioural correlations across situations and the evolution of antipredator behaviour in a sunfishsalamander system. Anim Behav 65(1):29-44

Sih A, Bell A, Johnson JC (2004) Behavioral syndromes: an ecological and evolutionary overview. Trends Ecol Evol 19(7):372-378

Simmons LW (1986) Inter-male competition and mating success in the field cricket, Gryllus bimaculatus (De Geer). Anim Behav 34(2): 567-579

Smith JM, Harper D (2003) Animal signals. Oxford University press, Oxford, UK

Stamps JA (2007) Growth-mortality tradeoffs and 'personality traits' in animals. Ecol Lett 10:355-363

Stamps JA, Groothuis TGG (2010) The development of animal personality: relevance, concepts and perspectives. Biol Rev 85:301-325

Staudacher EM (2009) The auditory system of last instars in Gryllus bimaculatus DeGeer. Physiol Entomol 34:18-29

Tigas LA, Van Vuren DH, Sauvajot RM (2002) Behavioural responses of bobcats and coyotes to habitat fragmentation and corridors in an urban environment. Biol Conserv 108:299-306

Tyack PL (2008) Implications for marine mammals of large-scale changes in the marine acoustic environment. J Mammal 89:549-558

Warren PS, Katti M, Ermann M, Brazel A (2006) Urban bioacoustics: it's not just noise. Anim Behav 71:491-502

Wilson ADM, Whattam EM, Bennett R, Visanuvimol L, Lauzon C, Bertram SM (2010) Behavioral correlations across activity, mating, exploration, aggression, and antipredator contexts in the European house cricket. Behav Ecol Sociobiol 64(5):703-715

Wolf M, Van Doorn GS, Leimar O, Weissing FJ (2007) Life-history trade-offs favour the evolution of animal personalities. Nature 447(7144):581-584

Publisher's note Springer Nature remains neutral with regard to jurisdictional claims in published maps and institutional affiliations. 